\title{
Factors Determining Periprocedural and Long-term Complications of High Risk Carotid Artery Stenting
}

\author{
Vincent Dinculescu, Anne C.M. Ritter, Marlise P. dos Santos, Ravi M. Mohan, \\ Betty A. Schwarz, Howard J. Lesiuk, Cheemun Lum
}

\begin{abstract}
Background and Purpose: Carotid artery stenting (CAS) has been, historically, an alternative to open endarterectomy (CEA) for stroke prevention in high risk patients with carotid atherosclerosis. We sought to determine the rates of periprocedural and longterm stroke or death and the risk factors for complications after CAS in our high risk patient population. Methods: Clinical and treatment variables of consecutive CAS procedures performed between 2002 and 2011 were analyzed. Using univariate and multivariate logistic regression analyses we examined how patient characteristics influenced outcomes and changes in modified Rankin Score (mRS). Results: In 152 patients, the composite total of periprocedural death, stroke, transient ischemic attack (TIA) and myocardial infarction (MI) rate was 3.95\% (6/152). Chronic kidney disease (CKD) was strongly associated with periprocedural complications $(\mathrm{p}<0.001)$. Coronary artery disease/peripheral vascular disease $(\mathrm{CAD} / \mathrm{PVD})(\mathrm{p}=0.03)$, dyslipidemia $(\mathrm{p}=0.02), \mathrm{CKD}(\mathrm{p}=0.01)$, and contralateral internal carotid artery stenosis $(\mathrm{p}=0.02)$ were non-modifiable risk factors for $\mathrm{mRS}$ increase. There were 25 deaths, 8 strokes, 11 TIAs, and $1 \mathrm{MI}$ (mean follow-up 38.4 months, range $0-116$ months). The presence of CAD/PVD $(p=0.009)$ and dyslipidemia $(p=0.002)$ were significantly associated with long-term complications. Conclusion: CAS was performed with low periprocedural complications in high-risk patients. Our rates compare very favorably to large-scale trials that have ideal patients. This data encourages the consideration of CAS in patients considered high risk for CEA and provides possible patient characteristics (CKD) to help with periprocedural risk stratification.
\end{abstract}

RÉSUMÉ: Mise en place d'une endoprothèse carotidienne chez des patients à haut risque: facteurs déterminants des complications périprocédurales et des complications à long terme. Contexte et but: Historiquement, la mise en place d'une endoprothèse carotidienne (EC) était une alternative à l'endartérectomie ouverte (EO) pour la prévention de l'accident vasculaire cérébral (AVC) chez les patients à haut risque atteints d'athérosclérose carotidienne. Le but de l'étude était de déterminer les taux d'AVC ou de décès périprocéduraux et à long terme ainsi que les facteurs de risque de complications après la mise en place d'une EC dans notre population de patients à haut risque. Méthode: Nous avons analysé les variables cliniques et thérapeutiques de la mise en place d'une EC effectuée chez des patients consécutifs entre 2002 et 2011. Nous avons examiné comment les caractéristiques des patients ont influencé l'issue et les changements du score à l'échelle modifiée de Rankin (SÉMR) au moyen de l'analyse de régression logistique univariée et multivariée. Résultats: Le taux total de décès périprocéduraux, d'AVC, d'ischémie cérébrale transitoire (ICT) et d'infarctus du myocarde (IM) était de 3,95\% (6/152). L'insuffisance rénale chronique (IRC) était fortement associée aux complications périprocédurales $(\mathrm{p}<0,001)$. La maladie coronarienne/la maladie vasculaire périphérique (MC/MVP) $(\mathrm{p}=0,03)$, la dyslipidémie $(\mathrm{p}=0,02)$, l'IRC $(\mathrm{p}=0,01)$ et la sténose carotidienne controlatérale $(\mathrm{p}=0,02)$ étaient des facteurs de risque non modifiables de l'augmentation du SÉMR. Vingt-cinq décès, 8 AVC, 11 ICT et 1 IM ont été rapportés (suivi moyen de 38,4 mois ; écart de 0 à 116 mois). La présence de MCAS/ MVP $(\mathrm{p}=0,009)$ et de dyslipidémie $(\mathrm{p}=0,002)$ étaient associées de façon significative aux complications à long terme. Conclusion: La mise en place d'une EC a été effectuée avec un faible taux de complications périprocédurales chez des patients à haut risque. Nos taux se comparent très favorablement à ceux d'essais à grande échelle qui recrutent des patients idéals. Ces données incitent à envisager la mise en place d'une EC chez des patients considérés à haut risque pour l'EO et indiquent quelles sont les caractéristiques qu'on doit prendre en compte pour la stratification des risques périprocéduraux.

Keywords: Carotid artery stenting, stenting, outcome, clinical outcome, long term

doi:10.1017/cjn.2014.125

Can J Neurol Sci. 2015; 42: 48-54

Carotid endarterectomy (CEA) has historically been shown to be an effective tool in the management of high risk extracranial occlusive disease. ${ }^{1-3}$ More recently, carotid artery angioplasty and stenting (CAS) has emerged as a less invasive alternative to CEA. The largest trial to date comparing CEA and CAS has been the Carotid Revascularization Endarterectomy versus Stenting Trial (CREST), which randomly assigned over two thousand patients to undergo either treatment. ${ }^{4}$ CREST's results showed no statistical significant difference in the composite outcomes of death, stroke, or myocardial infarction (MI) between CEA and CAS, however during the periprocedural period (30 days after procedure) there was a higher risk of stroke with $\mathrm{CAS}^{4}$ This conclusion was further supported in the recent meta-analysis by Yavin et al. ${ }^{5}$ Follow-up analysis of CREST results have shown

From the Faculty of Medicine (VD); Department of Neurosurgery (HJL), University of Ottawa; Department of Diagnostic Imaging (MPdS, BAS, CL), The Ottawa Hospital,

Ottawa; Department of Medical Imaging (RMM), University of Toronto, Toronto, Ontario, Canada; Royal College of Surgeons in Ireland (ACMR), Dublin, Ireland. Received July 20, 2014. Final Revisions Submitted November 25, 2014. Correspondence to: Marlise P. dos Santos, Department of Medical Imaging, The Ottawa Hospital, 01-1-10-A - 1053 Carling Avenue, K1Y 4E9 Ottawa, Ontario, Canada. Email: msantos@toh.on.ca 
that patients under the age of 70 have similar risks with CEA and CAS, however the risk increases in those patients over the age of 70 undergoing CAS; patient risk increases based on age. $^{6}$ A meta-analysis that pooled results from previous studies including the International Carotid Stenting Study, Endarterectomy Versus Angioplasty in Patients with Symptomatic Severe Carotid Stenosis (EVA-3s) and stent-protected angioplasty versus carotid endarterectomy (SPACE) has reached a similar conclusion that CAS might be as safe as CEA in younger patients (age $<70){ }^{7}$ These conclusions are reflected in the recently published American Heart Association/American Stroke Association (AHA/ASA) guidelines for prevention of stroke which state CEA is associated with improved outcomes in this age group. ${ }^{8}$

In large studies such as CREST, randomized patients are medically fit to undergo either CEA or CAS, meaning these patients are in relatively good health. ${ }^{4}$ In clinical practice however, patients are pragmatically selected to CAS if they are ineligible (high risk) for CEA; a routine that clashes with the recent guidelines. ${ }^{8} \mathrm{~A}$ historical cohort of CAS patients considered high risk for revascularization treatment provides an opportunity to study the most significant causes and consequences of adverse events.

Our primary goal was to determine the rates of periprocedural and long-term death, stroke, transient ischemic attach (TIA), or MI and identify the risk factors associated with complications after CAS in our high risk patients. Secondarily, we compared our rates of complications with those reported in the recent literature.

\section{MethodS}

\section{Patient Data Collection}

We retrospectively collected patient data from patients who presented with carotid stenosis of $>70 \%$ as determined by ultrasound, computed tomography angiography (CTA), or digital subtraction angiography (DSA), and were subsequently treated using CAS between September 2002 and August 2011. We reviewed the inpatient records, pre/post procedural notes, operative notes and radiologic reports to collect patient data including clinical, demographic, procedural technique, modified Rankin Score (mRS), and the procedure outcome data. Clinical data included history of systemic hypertension (blood pressure $>140 / 90$ or use of hypertensive medication at time of procedure), stroke, TIA, stages 3-5 chronic kidney disease (CKD - estimated glomerular filtration rate (eGFR) <60), dyslipidemia (low density lipoprotein $>2.0$ ), atrial fibrillation, diabetes mellitus (use of antidiabetic medication at time of procedure), chronic obstruction pulmonary disease, previous coronary artery disease or peripheral vascular disease (CAD/ PVD), indications for CAS, contralateral internal carotid artery (ICA) stenosis, length of hospital stay, suitability for CEA, symptoms pre-CAS, and smoking status. Demographic data consists of age and sex. Procedure related data consisted of type of stent used and employment of pre or post stent angioplasty. We collected procedure outcome data including the events: death, stroke, TIA, and MI. Other periprocedural outcomes recorded were postprocedural hypotension, groin hematoma requiring vascular surgical repair, right external iliac thrombosis, and heparin induced thrombocytopenia syndrome during CAS procedure. We defined two time frames, periprocedural and long-term; periprocedural complication is defined as death, stroke, TIA or MI occurring within 30 days of the procedure, and long-term complication is defined as death, stroke, TIA, or MI occurring after 30 days of the procedure. The functional status of all patients was determined using the $\mathrm{mRS}^{9}$ at both a pre-procedure and last clinical encounter dates by clinicians not involved in the CAS procedure. This study was approved by our institutional research ethics board.

\section{CAS Technique}

All patients received dual anti-platelet therapy for a minimum of five days before device implantation using aspirin $(81 \mathrm{mg})$ and clopidogrel (75 mg) orally, once per day. We intended to position a distal embolic protection device in all cases. We performed a pre-stenting angioplasty when the stenosis was too severe to allow crossing of the protection device. We performed a post stenting angioplasty if residual stenosis was noted or brain perfusion was limited after positioning the stent. All patients underwent independent neurological evaluation before and after CAS and during follow-up at 30 days, six months, and annually.

\section{Statistical analysis}

Patients with previous neck radiation were excluded. Clinical data included history of: CAD-PVD, stroke, TIA, ipsilateral past CEA, dyslipidemia, hypertension, congestive heart failure, atrial fibrillation, smoking, diabetes, Chronic obstructive pulmonary disease, chronic kidney disease, CEA suitability, and initial diagnosis. Demographics included age and sex. To compare clinical data within age subgroups, logistic regression analysis was performed. To detect risk factors associated with mRS increase logistic regression analysis was conducted after adjusting for pre-stent mRS (0-2 vs. 3-5). Bootstrap method was used for internal validation of the final multivariate logistic model. Logistic regression analysis was also used for detecting the association between clinical/demographic variables and the outcomes: periprocedural/long-term complications, hospital stay $>2$ days. $\mathrm{R}^{2}$ was used to measure the model fit. ${ }^{10}$ Cox Proportional Hazard model was performed in the overall survival analysis. Fisher exact test was applied for detecting the relationship between periprocedural/long-term complications and contralateral ICA stenosis, between mRS increase and protection device, stent type, or post-CAS angiography. P-value $<0.05$ was considered statistically significant.

\section{Results \\ Patient characteristics}

We identified a total of 156 patients treated with CAS at our institution. Four of these patients had prior neck radiation and were excluded from the results and statistical analysis.

Our entire cohort used in the statistical analysis consisted of 152 patients of which $128(84 \%)$ had symptomatic carotid stenosis. Patient characteristics are described in Table 1 . The mean age was $71.4 \pm 10.0$, with $114(75 \%)$ male subjects. We had $67(44 \%)$ patients younger than 70 years of age, eighty-five $(55.9 \%)$ patients $\geq 70$ years of age, and $38(25 \%)$ patients $\geq 80$ years of age. The most common indications for CAS were transient ischemic attack in $63(41 \%)$ patients, stroke in $40(27 \%)$ patients, ocular ischemia in $19(13 \%)$ patients, and CEA restenosis in $10(6 \%)$ patients. Based on interdisciplinary assessment, $16(10 \%)$ patients were suitable for either CAS or CEA and opted to undergo CAS, whereas the remainder patients were considered not ideal for CEA.

The relationships between the selected age subgroups and demographic/clinical data are displayed in Table 2. Those aged 
Table 1: Patient characteristics represented by total patient number with percentage of total patient population in brackets

\begin{tabular}{l|c}
\hline Patient Characteristics & \\
\hline Atrial fibrillation & $16(10.53 \%)$ \\
\hline Carotid endarterectomy in the past & $20(13.16 \%)$ \\
\hline Chronic kidney disease & $15(9.87 \%)$ \\
\hline Chronic obstructive pulmonary disease & $20(13.16 \%)$ \\
\hline Congestive heart failure & $10(6.58 \%)$ \\
\hline Coronary artery sisease/ peripheral vascular disease & $86(56.58 \%)$ \\
\hline Diabetes mellitus & $64(42.11 \%)$ \\
\hline Dyslipidemia & $113(74.34 \%)$ \\
\hline Hypertension & $120(78.95 \%)$ \\
\hline Smoking & $65(42.76 \%)$ \\
\hline Stroke/Transient ischemic Aattack & $113(74.34 \%)$ \\
\hline Symptomatic Pre-CAS & $128(84.21 \%)$ \\
\hline
\end{tabular}

$>70$ were more likely to have atrial fibrillation $(p=0.01)$ but less likely to have diabetes mellitus $(p=0.02)$, smoking $(p=0.002)$, history of CEA $(p=0.049)$, or stroke/TIA $(p=0.02)$. Those aged $>80$ were found to be less likely to have diabetes mellitus $(\mathrm{p}=0.03)$.
In $131(86 \%)$ procedures we employed the use of a distal embolic protection device. We placed a single stent device in 149 $(98 \%)$ procedures. We performed post-CAS angioplasty in 81 $(53 \%)$ procedures.

\section{Primary Endpoints}

The mean time to treatment was $87 \pm 186$ days with a range of 0 to 1708 days. The median post-procedural length of hospital stay was two days (mean absolute difference $=1$ ). Pre-stent mRS 3-5 was significantly associated with length of hospital stay $>$ two days (odds ration (OR) 2.933 confidence interval (CI)[1.2696.886]).

The total follow-up time was 5,837 months with a mean follow-up of 38.4 months per patient. Figure 1 describes the distribution of frequencies of follow up time in the entire cohort.

Pre-CAS mRS and $\mathrm{mRS}$ at last clinical encounter are shown in Figure 2. The majority of patients $(143[94 \%])$ had a pre-stent $\mathrm{mRS} \leq 3$. Thirty-nine (26\%) patients had a $\mathrm{mRS}$ increase at the last clinical encounter after CAS. We found that CAD/PVD $(\mathrm{p}=0.03)$, dyslipidemia $(\mathrm{p}=0.02)$, CKD $(\mathrm{p}=0.01)$, and contralateral ICA stenosis $(\mathrm{p}=0.02)$ were non-modifiable risk factors associated with $\mathrm{mRS}$ increase after CAS. These factors remained significant when placed into multivariate analysis and were confirmed via bootstrapping. We found that age $>70(\mathrm{p}=0.26)$, age $>80(\mathrm{p}=0.23)$, initial diagnosis of stroke $(\mathrm{p}=0.27)$ or TIA

Table 2: Association of patient characteristics to age greater than 80. Bolded values are statistically significant

\begin{tabular}{|c|c|c|c|}
\hline Patient Characteristics & Age Range & p-value & OR $(95 \% \mathrm{Cl})$ \\
\hline \multirow[t]{2}{*}{ Atrial fibrillation } & Age $\geq 70$ & 0.0114 & $14.143(2.747,259.171)$ \\
\hline & Age $\geq 80$ & 0.2285 & $1.950(0.622,5.680)$ \\
\hline \multirow[t]{2}{*}{ Carotid endarterectomy in the past } & Age $\geq 70$ & 0.0489 & $0.373(0.132,0.972)$ \\
\hline & Age $\geq 80$ & 0.5810 & $0.721(0.196,2.128)$ \\
\hline \multirow[t]{2}{*}{ Chronic kidney disease } & Age $\geq 70$ & 0.7378 & $1.204(0.411,3.765)$ \\
\hline & Age $\geq 80$ & 0.6390 & $0.729(0.159,2.456)$ \\
\hline \multirow[t]{2}{*}{ Congestive heart failure } & Age $\geq 70$ & 0.3606 & $1.915(0.510,9.157)$ \\
\hline & Age $\geq 80$ & 0.7062 & $1.310(0.271,4.994)$ \\
\hline \multirow[t]{2}{*}{ Coronary artery disease/Peripheral vascular disease } & Age $\geq 70$ & 0.7189 & $0.888(0.463,1.695)$ \\
\hline & Age $\geq 80$ & 0.1879 & $0.609(0.289,1.274)$ \\
\hline \multirow[t]{2}{*}{ Congestive heart failure } & Age $\geq 70$ & 0.3606 & $1.915(0.510,9.157)$ \\
\hline & Age $\geq 80$ & 0.7062 & $1.310(0.271,4.994)$ \\
\hline \multirow[t]{2}{*}{ Diabetes mellitus } & Age $\geq 70$ & 0.0256 & $0.473(0.244,0.909)$ \\
\hline & Age $\geq 80$ & 0.0254 & $0.397(0.170,0.869)$ \\
\hline \multirow[t]{2}{*}{ Dyslipidemia } & Age $\geq 70$ & 0.2346 & $0.634(0.293,1.329)$ \\
\hline & Age $\geq 80$ & 0.7478 & $1.151(0.502,2.829)$ \\
\hline \multirow[t]{2}{*}{ Hypertension } & Age $\geq 70$ & 0.4485 & $1.353(0.616,2.973)$ \\
\hline & Age $\geq 80$ & 0.3609 & $1.576(0.626,4.541)$ \\
\hline \multirow[t]{2}{*}{ Smoking } & Age $\geq 70$ & 0.0023 & $0.355(0.181,0.686)$ \\
\hline & Age $\geq 80$ & 0.1105 & $0.531(0.238,1.136)$ \\
\hline \multirow[t]{2}{*}{ Stroke/TIA } & Age $\geq 70$ & 0.0228 & $0.400(0.176,0.861)$ \\
\hline & Age $\geq 80$ & 0.5923 & $0.799(0.357,1.867)$ \\
\hline
\end{tabular}

TIA $=$ transient ischemic attack; $\mathrm{OR}=$ odds ratio $\mathrm{CI}=$ confidence interval 


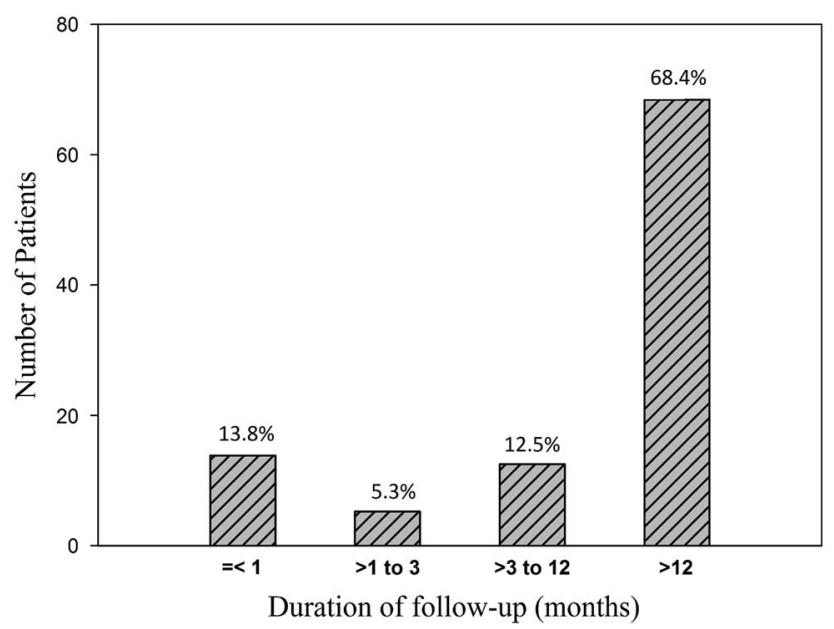

Figure 1: Distribution of follow-up divided into four chronological categories with raw patient numbers in each group on $x$-axis and percentages located above each barn.

$(p=0.82)$, or sex $(p=0.72)$, were not associated with an increase in $\mathrm{mRS}$ after CAS.

Periprocedural complications are listed in Table 3. We found two $(1.32 \%)$ deaths, one $(0.66 \%)$ transient ischemic attack, three $(1.97 \%)$ strokes, and no cardiac complications. Characteristics of the three strokes are located in Table 4. Four (2.63\%) patients incurred non-life threatening complications classified as "Other". The two periprocedural deaths were due to multiple organ infarctions (due to embolic phenomenon) and immediate post procedural intracranial (intraventricular and subarachnoid) hemorrhages. The composite total of death, stroke, TIA, and MI rate was $3.95 \%$ (6/152). The presence of CKD was significantly associated with periprocedural complications $(\mathrm{p}=0.004$ OR 10.763 CI [2.081-56.193]).

Long-term complications are listed in Table 3 . The mean time to mortality was $1131 \pm 762$ days with a range of 1 to 3205 . There were $25(16 \%)$ deaths, $8(5 \%)$ strokes, $11(7 \%)$ TIAs, and 1

\section{Table 3: Periprocedural and long-term complication rate. Total patient number with percentage of total patients in brackets}

\begin{tabular}{l|c}
\hline Procedure Outcomes $(\mathbf{N}=\mathbf{1 5 2})$ & \\
\hline Periprocedural Complications $(\leq 30$ days after CAS $)$ & $142(93.42 \%)$ \\
\hline No complication & $2(1.32 \%)$ \\
\hline Death & $3(1.97 \%)$ \\
\hline Stroke & $1(0.66 \%)$ \\
\hline TIA & $4(2.63 \%)$ \\
\hline Other & $102(67.11 \%)$ \\
\hline Long-term Complications $(>30$ days after CAS) & $25(16.45 \%)$ \\
\hline No complication & $8(5.26 \%)$ \\
\hline Death & $11(7.24 \%)$ \\
\hline Stroke & $19(12.5 \%)$ \\
\hline TIA & $1(0.66 \%)$ \\
\hline Stroke + TIA combined & $5(3.29 \%)$ \\
\hline Myocardial infarction & \\
\hline Other & \\
\hline
\end{tabular}

$\mathrm{TIA}=$ transient ischemic attack $\mathrm{CAS}=$ carotid artery stenting

$(0.66 \%)$ MI. The presence of CAD/PVD $(p=0.009)$ and dyslipidemia $(p=0.002)$ were significantly associated with long-term complications.

The Cox proportional hazard model analysis showed that CAD/PVD $(p=0.004)$ along with CKD $(p<0.001)$ was related to overall survival after CAS. These variables remained significant in multivariable analysis of overall survival. The Kaplan-Meier survival curves were created to examine the difference in survival between patients with either: CKD, CAD/PVD, symptomatic carotid stenosis or age $\geq 70$ years. The graphs are shown Fig. 3 and depict that $\mathrm{CKD}$ and $\mathrm{CAD} / \mathrm{PVD}$ were significantly related to survival by log rank test.

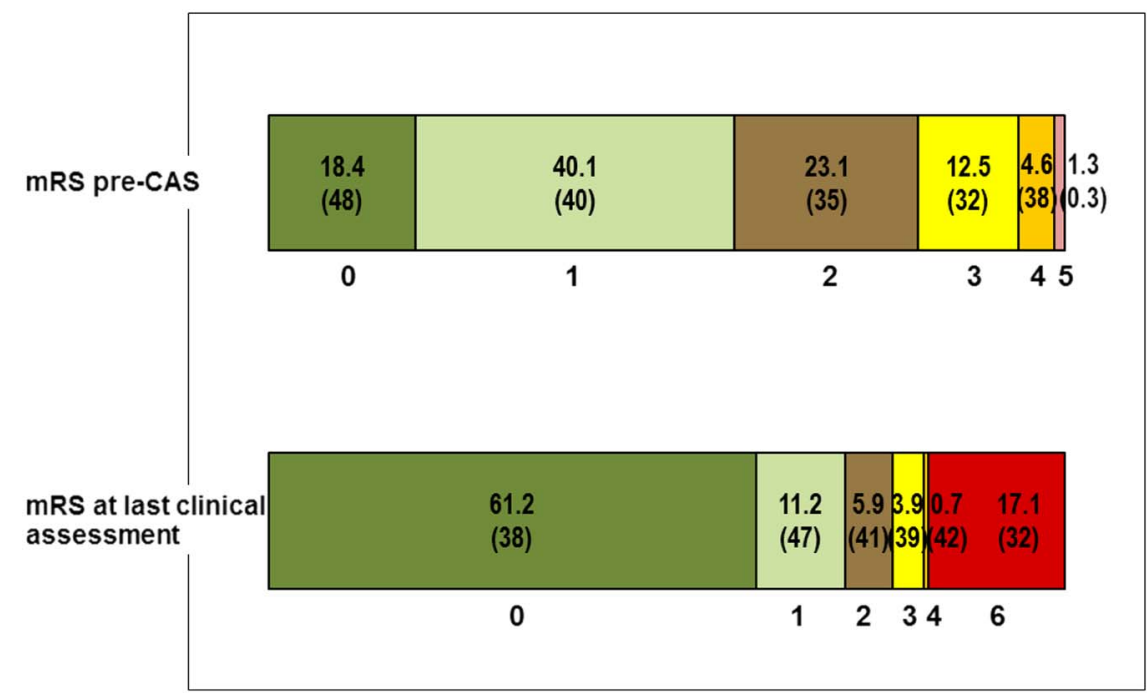

Figure 2: Modified Rankin Score distribution both pre-CAS and at last clinical assessment. Overlaid numbers represent percentage with mean follow up time for each group located in adjacent brackets. No patient received a mRS of 5 at last clinical assessment. 
Table 4: Characteristic of three patients who suffered stroke in the periprocedural time frame

\begin{tabular}{l|l|c|c}
\hline Patient & Periprocedural stroke & Side of stented carotid & Patient Characteristics \\
\hline $\mathbf{2 0}$ & Left side Intracranial Hemorrhage & Left Side & Previous Stroke/TIA \\
\hline & & & Hypertension \\
\hline & & & Dyslipidemia \\
\hline & & & Smoking \\
\hline & & Diabetes \\
\hline $\mathbf{1 3 4}$ & Left basal ganglia and internal capsule intracerebral hemorrhage & CAD/PVD & Dyslipidemia \\
\hline & & & Hypertension \\
\hline $\mathbf{1 5 6}$ & & & Previous Stoke/TIA \\
\hline & Left sided Facial drop and hemiparesis & Right side & Hypertension \\
\hline & & & smoking \\
\hline
\end{tabular}

$\mathrm{TIA}=$ transient ischemic attack; $\mathrm{CAD} / \mathrm{PVD}=$ coronary artery disease/peripheral vascular disease

Contralateral ICA stenosis was not a risk factor for periprocedural $(\mathrm{p}=0.74)$ or long-term complications $(\mathrm{p}=0.28)$. As expected, suitability for CEA was not associated with mRS increase $(p=0.07)$ or complications within $(p=0.52)$ or after 30 days $(\mathrm{p}=0.68)$.

\section{DISCUSSION}

The data we describe here reflects a practice where CEA is the first line of treatment for patients with symptomatic carotid stenosis. CAS is pragmatically chosen as an alternative when patients are unsuitable for or refuse CEA. These selection criteria imply that the inherent population of this study was deemed higher risk compared to the background of patients with stenosis.
The decision to remove patients with prior neck radiation from the analysis was made because of the inherent lower longevity and higher risk of stroke in this patient population. ${ }^{11}$

\section{Periprocedural Complication Rate}

The periprocedural complication rate at our center, $3.95 \%$, compares favorably with rates found in the recent literature. The CAS arm of CREST, which had an ideal patient population, reported a periprocedural rate of death, stroke, or MI of $5.9 \%$. $^{4}$ Case series reports in high risk patients report periprocedural rates range between $2.6-8.2 \%{ }^{12-14}$ Interim analysis of CREST data brought light to the idea that octogenarians have an increased risk of periprocedural complications. ${ }^{15}$ A study further examining
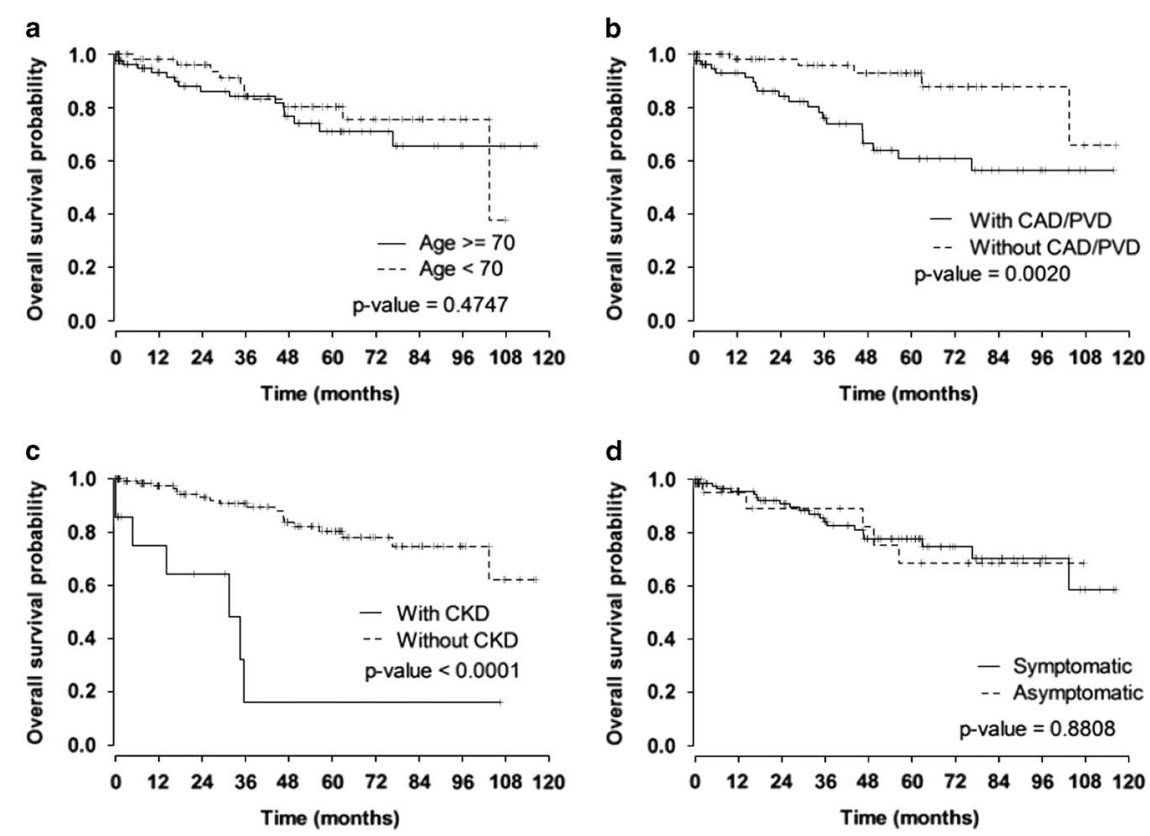

Figure 3: Kaplan-Meier Overall Survival curve with 95\% CI in all patients. A) age $\geq 70$ or age $<70$. B) with or without $C A D / P V D$. C) with or without $C K D$. D) symptomatic vs. asymptomatic 
octogenarian CAS risk concluded that it was equal to CEA risk if good indications, meticulous techniques, and protection devices were used. ${ }^{16}$ Recently published AHA/ASA guidelines moved this age division down to 70 stating that CEA may be more appropriate for patients older than 70 but that CAS should be considered as equivalent for CEA in terms of periprocedural complications in those younger than $70 .^{8}$ This is supported by the recent case series by Alkins et al. that examined 159 patients who underwent CAS and concluded that CAS might be a safe alternative for those under 70 but in those over 70 careful patient selection is needed. ${ }^{14}$ Likely due to selection bias, our data is contrary to both of these conclusions as we found that age (using either the 70 or 80 cut off) was not significantly associated with periprocedural complication rate. Rather age, when using the $>70$ cut off, seemed to be protective for some of the patient characteristics we found, meaning that older patients actually had fewer comorbidities. From this we suggest that age might not play as important a factor in outcomes of CAS as previously believed.

It is apparent in our series that CKD is a risk factor associated with periprocedural complications and with long-term disability and death in patients undergoing CAS. Previous case reports similarly demonstrated that CKD was associated with higher rates of complications after CAS. ${ }^{17}$ This is in contrast to the recent Care Registry analysis which showed, after risk factor adjustment, that CKD was not an independent predictor 30-day outcome. ${ }^{18}$ A recent study done by AbuRahma et al. sought to understand what role CKD plays in outcomes of CEA and found that patients with moderate to severe CKD (GFR <60) had an significant increased odds ratio for early stroke or death. ${ }^{19}$ His data suggested that CEA would not be a suitable alternative to CAS in patients with CKD.

\section{Long-term Study}

In contrast to previous studies evaluating long-term data in CAS, our study population was unique in that it provided reliable outcome data beyond 30 days. Less than one third of our patients had long term complications of stroke or MI. Our long-term mortality rate, $16 \%$, is lower than that previously reported. The SAPHIRE study showed at three-year follow up the combined death, stroke, or MI rate was $24.6 \% .^{20}$ CREST showed at fouryear follow up the combined stroke, MI, or death rate was $27.7 \% .^{4}$ Recent cases series report all-cause mortality rates to range from $16.8-47.5 \%$ within five years. ${ }^{12,21,22}$ Brooks et al. conducted a randomized trial to compare the ten-year efficacy of CAS versus CEA and found 50\% mortality in those who achieved follow up of ten years, and most commonly of nonvascular causes. ${ }^{23}$ This wide range found in the literature likely implies that the patient populations within these various studies were heterogeneous. Additionally, CKD was a risk factor for long-term mortality placing further emphasis on the potential need for more rigorous surveillance.

\section{Modified Rankin Score Analysis}

We examined changes in mRS in patients undergoing CAS. This allowed the identification of factors relating to functional decline as opposed to solely examining death, stroke, TIA, or MI rates. A majority of our patients gained a benefit in functioning post CAS. The previously described age categories ( $>70$ or $>80$ years of age) were not related to $\mathrm{mRS}$ increase. The risk factors related to long-term mRS increase after CAS
(CAD/PVD, dyslipidemia, CKD, contralateral ICA stenosis) suggest that atherosclerosis-related diseases contribute to the decline in patients functioning over time. Because of the sparse data published in this area, it is not possible to compare our rates. However, based on our data pre-CAS mRS could serve in determining which patients will have a longer length of hospital stay and a more complicated clinical course after CAS.

\section{Limitations}

We cannot exclude the possibility of residual confounding factors related to the retrospectively analyzed data. Given the pragmatic limitations of our practice we do not have a large lowrisk CAS group for comparison. Although a regular clinical follow up schedule was desired, it was not achieved in all patients; this might have interfered with timing of detection of complications. Because we observed so few periprocedural complications, the power to statistically evaluate the factors contributing to these outcomes could have been insufficient. Since our mRS assessment was done at the last clinical encounter the improvement cannot solely be attributed to CAS.

\section{Conclusion}

Survival analysis in this retrospective cohort with long-term follow up data found that our periprocedural and long-term complication rates in a high risk population compare favorably to large scale trials that have ideal patients. We identified CKD as a significant risk factor for periprocedural complications and long-term $\mathrm{mRS}$ increase. Age was not associated with periprocedural outcomes, increase in $\mathrm{mRS}$, long-term complications and long-term mortality. We identified $\mathrm{mRS}$ as a possible predictive tool and reported rates than can be used for comparison in future studies. This data encourages the consideration of CAS for patients considered to be high risk for CEA who need therapy for carotid atherosclerotic burden and provides possible patient characteristics (CKD) to help with risk stratification.

\section{ACKNOWLEDGEMENTS}

We would like to thank Dr. Liying Zhang PhD, Senior Statistician MacroStat Inc., for her help with statistical analysis. We thank Mrs. Christina Tsoukanas for research and administrative assistance.

\section{Statement of Authorship}

VD and ACMR made an equal contribution to this work and should be considered joint first authors.

\section{Disclosures}

We declare that we have no conflicts of interest.

\section{REFERENCES}

1. European Carotid Surgery Trialists' Collaborative Group. MRC European Carotid Surgery Trial: interim results for symptomatic patients with severe $(70-99 \%)$ or with mild $(0-29 \%)$ carotid stenosis. Lancet. 1991;337:1235-43.

2. North American Symptomatic Carotid Endarterectomy Trial Collaborators Beneficial effect of carotid endarterectomy in symptomatic patients with high-grade carotid stenosis. N Engl J Med. 1991;325:445-53. 
3. Executive Committee for the Asymptomatic Carotid Atherosclerosis Study. Endarterectomy for asymptomatic carotid artery stenosis. JAMA. 1995;273:1421-8.

4. Brott TG, Hobson RW, 2nd, Howard G, et al. Stenting versus endarterectomy for treatment of carotid-artery stenosis. N Engl J Med. 2010;363:11-23.

5. Yavin D, Roberts DJ, Tso M, Sutherland GR, Eliasziw M, Wong JH. Carotid endarterectomy versus stenting: a meta-analysis of randomized trials. Can J Neurol Sci. 2011;38:230-5.

6. Voeks JH, Howard G, Roubin GS, et al. Age and outcomes after carotid stenting and endarterectomy: the carotid revascularization endarterectomy versus stenting trial. Stroke. 2011;42:3484-90.

7. Carotid Stenting Trialists Collaboration, Bonati LH, Dobson J, Algra A, et al. Short-term outcome after stenting versus endarterectomy for symptomatic carotid stenosis: a preplanned meta-analysis of individual patient data. Lancet. 2010;376:1062-73.

8. Kernan WN, Ovbiagele B, Black HR, et al., on behalf of the American Heart Association Stroke Council CoC, Stroke Nursing CoCC, Council on Peripheral Vascular D. Guidelines for the Prevention of Stroke in Patients With Stroke and Transient Ischemic Attack: A Guideline for Healthcare Professionals From the American Heart Association/American Stroke Association. Stroke. 2014;45:2160-236.

9. Farrell B, Godwin J, Richards S, Warlow C. The United Kingdom transient ischaemic attack (UK-TIA) aspirin trial: final results. J Neurol Neurosurg Psychiatry. 1991;54:1044-54.

10. SAS Institute Inc. SAS/STAT 9.2 User's Guide: The Logistic Procedure In 2008 SAS Institute Inc, Cary, NC, USA.

11. Plummer C, Henderson RD, O'Sullivan JD, Read SJ. Ischemic stroke and transient ischemic attack after head and neck radiotherapy: a review. Stroke. 2011;42:2410-8.

12. Gribar JJ, Jiddou M, Choksi N, et al. Carotid stenting in high-risk patients: early and late outcomes. J Interv Cardiol. 2011;24:247-53.

13. Chiam PT, Roubin GS, Panagopoulos G, et al. One-year clinical outcomes, midterm survival, and predictors of mortality after carotid stenting in elderly patients. Circulation. 2009;119:2343-8.
14. Alkins R, Matouk CC, Cruz JP, Marotta T, Montanera W, Spears J. Carotid artery angioplasty and stenting for patients less than 70 years-of-age. Can J Neurol Sci. 2012;39:338-42.

15. Hobson RW, 2nd, Howard VJ, Roubin GS, et al. Carotid artery stenting is associated with increased complications in octogenarians: 30-day stroke and death rates in the CREST lead-in phase. J Vasc Surg. 2004;40:1106-11.

16. Henry M, Henry I, Polydorou A, Hugel M. Carotid angioplasty and stenting in octogenarians: is it safe? Catheter Cardiovasc Interv. 2008;72:309-17.

17. Saw J, Gurm HS, Fathi RB, et al. Effect of chronic kidney disease on outcomes after carotid artery stenting. Am J Cardiol. 2004;94: 1093-6.

18. Gruberg L, Jeremias A, Rundback JH, et al. Impact of glomerular filtration rate on clinical outcomes following carotid artery revascularization in 11,832 patients from the care registry(R). Catheter Cardiovasc Interv. 2014;84:246-54.

19. AbuRahma AF, Srivastava M, Chong B, Dean LS, Stone PA, Koszewski A. Impact of chronic renal insufficiency using serum creatinine vs glomerular filtration rate on perioperative clinical outcomes of carotid endarterectomy. J Am Coll Surg. 2013;216:525-32; discussion 532.

20. Gurm HS, Yadav JS, Fayad P, et al., SAPPHIRE Investigators. Long-term results of carotid stenting versus endarterectomy in high-risk patients. N Engl J Med. 2008;358:1572-9.

21. Lago A, Parkhutik V, Tembl JI, et al., Long-term outcome in patients with carotid artery stenting and contralateral carotid occlusion: a single neurovascular center prospective analysis. Neuroradiology. 2012;54:965-72.

22. Eskandari MK, Usman AA, Garcia-Toca M, et al. Eight-year institutional review of carotid artery stenting. J Vasc Surg. 2010;51: 1145-51.

23. Brooks WH, Jones MR, Gisler P, et al. Carotid angioplasty with stenting versus endarterectomy: 10-year randomized trial in a community hospital. JACC Cardiovasc Interv. 2014;7: 163-168. 